\title{
ATENÇÃO INTEGRAL À SAÚDE COMO ESTRATÉGIA PARAA INTEGRAÇÃO ENSINO-SERVIÇO-COMUNIDADE: EXTENSÃO UNIVERSITÁRIA NA ÁREA DA SAÚDE DURANTE PANDEMIA DE COVID-191
}

\author{
COMPREHENSIVE HEALTH CARE AS A STRATEGY FOR \\ EDUCATION-SERVICE-COMMUNITY INTEGRATION: UNIVERSITY EXTENSION \\ IN THE HEALTH AREA DURING THE COVID-19 PANDEMY
}

\author{
Aline Krüger Batista ${ }^{2}$, Naiana Oliveira dos $\operatorname{Santos}^{3}$ e Janilse Fernandes Nunes ${ }^{4}$
}

\section{RESUMO}

Objetivo: relatar a experiência da curricularização da extensão universitária na área da saúde durante a pandemia de Covid-19. Metodologia: estudo descritivo, do tipo relato de experiência, desenvolvido a partir da curricularização da extensão do projeto integrador da área da saúde da [texto ocultado], localizada no [texto ocultado]. Foram 33 subprojetos que ocorreram durante o ano de 2020. Resultados: O projeto de extensão integrador da área da saúde denominado Atenção integral à saúde como estratégia para a integração ensino-serviço-comunidade integra oito cursos da área da saúde. A metodologia foi a Espiral Construtivista. Os avanços percebidos pelos docentes foi poder explorar o meio virtual para maior divulgação e alcance de informações, assim como o meio virtual agilizou e otimizou reuniões e encontros com a comunidade e estudantes. Conclusão: as atividades extensionistas desenvolvidas nos subprojetos promoveram a educação interprofissional e a atenção integral à saúde das comunidades desenvolvidas de forma virtual ou pelo envio de materiais para a comunidade.

Palavras-chave: Atenção Integral à Saúde; Extensão Comunitária; Promoção da saúde.

\section{ABSTRACT}

Objective: report the experience of the curricularization of university extension in the health area during the Covid-19 pandemic. Methodology: descriptive study of the experience report type, developed from the curricularization of the extension of the integrative project in the health area of the [texto ocultado], located in [texto ocultado]. There were 33 subprojects that took place during 2020. Results: The integrative extension project in the health area called Comprehensive Health Care as a strategy for teaching-servicecommunity integration includes eight courses in the health area. The methodology was the Constructivist Spiral. The advances perceived by the professors were being able to explore the virtual environment for greater dissemination and reach of information, as well as the virtual environment streamlined and optimized meetings with the community and students. Conclusion: the extension activities developed in the subprojects promoted interprofessional education and comprehensive health care in communities developed virtually or by sending materials to the community.

Keywords: Comprehensive Health Care, Community-Institutional Relations, Health Promotion.

1 Relato de experiência

2 Docente do curso de Odontologia da Universidade Franciscana-Santa Maria/RS. E-mail: aline.kruger@prof.ufn.edu.br 3 Docente do curso de Enfermagem da Universidade Franciscana-Santa Maria/RS. E-mail: naiana.santos@prof.ufn.edu.br 4 Docente no Programa de Pós-Graduação em Ensino de Ciências e Matemática da Universidade Franciscana-Santa Maria/RS. E-mail: janilse@ufn.edu.br 


\section{INTRODUÇÃO}

No Brasil, a extensão universitária como é hoje só emergiu em 1960, quando surgiram ações voltadas para as classes mais vulneráveis. Hoje a extensão universitária é considerada um dos pilares do ensino superior, que preconiza a formação profissional e humanística e também a transformação social (DESLANDES, 2017). Na prática, duas vertentes de Extensão Universitária têm se confrontado: uma mais assistencialista e outra não assistencialista. A primeira entende a extensão universitária como a transmissão vertical do conhecimento, um serviço assistencial, desconhecendo a cultura e o saber popular. A segunda vertente entende a extensão como comunicação de saberes (GADOTTI, 2017).

A curricularização da extensão universitária apareceu primeiramente no Plano Nacional de Educação (PNE) instituindo a "obrigatoriedade de 10\% dos créditos curriculares exigidos para a graduação, integralizados em ações extensionistas" (BRASIL, 2011). Essa obrigatoriedade reapareceu no PNE de 2014-2023: “assegurar, no mínimo, 10\% do total de créditos curriculares exigidos para a graduação em programas e projetos de extensão universitária, orientando sua ação, prioritariamente, para áreas de grande pertinência social”. (BRASIL, 2014). Observe-se a existência de importante avanço entre a visão da extensão universitária do primeiro para o segundo PNE: o PNE de 2014 sustenta uma visão mais popular e emancipatória, representada pela prioridade que é dada à atuação em “áreas de grande pertinência social” (GADOTTI, 2017).

Para a formação na área da saúde a extensão é essencial, pois possibilita experiências ampliadas de atuação em cenários do trabalho em saúde (BISCARDE et al., 2014). Dentro do contexto de formação em saúde, a extensão promove o reconhecimento do cuidado e das vivências com a sociedade. Sendo assim, a curricularização da extensão faz parte, de um lado, da indissociabilidade do ensino, da pesquisa e da extensão na universidade, e, de outro, da necessária conexão da universidade com a sociedade, realçando o papel social da universidade, bem como a relevância social do ensino e da pesquisa (GADOTTI, 2017). Representa uma possibilidade na qual o estudante pode colaborar com a comunidade, e de uma forma não assistencialista, ocorrer uma troca de saberes entre o estudante e o cidadão, que tem por consequência não só a democratização do conhecimento acadêmico, mas, igualmente, uma produção científica, tecnológica e cultural enraizada na realidade. E assim, produzir um conhecimento acadêmico e científico de alto nível em favor do cidadão, podendo transpor as barreiras existentes entre a sociedade e a universidade e desta forma interferir diretamente na perspectiva de realidade profissional (GADOTTI, 2017; SILVA, 2013).

Dentro desta perspectiva, existe desde 2018 o projeto de extensão integrador da [texto ocultado] ([texto ocultado],), nomeado de Atenção integral à saúde como estratégia para a integração ensino-serviço-comunidade, pertencente aos cursos da área da saúde. O projeto justifica-se pela compreensão da atividade de extensão como processo sistematizado e dinâmico que incorpora ações acadêmicas às necessidades da comunidade e à formação de profissionais protagonistas, com vistas 
às transformações sociais. Nesse contexto, a atenção integral à saúde representa uma estratégia para a integração ensino-serviço-comunidade que permite conhecer e agir frente às necessidades do ser humano dentro do seu contexto, o ambiente em que vive, personalizando cada contato dentro dos princípios da humanização.

O compartilhamento de saberes e práticas interprofissionais em saúde entre a academia e a comunidade torna-se, portanto, um terreno fértil para a promoção da saúde em diferentes cenários de atuação. O presente estudo objetiva relatar a experiência da curricularização da extensão universitária na área da saúde durante a pandemia de Covid-19.

\section{MÉTODO}

O método de estudo consiste em um relato de experiência acerca da curricularização das disciplinas extensionistas da área da saúde durante a pandemia da COVID-19, no ano de 2020. A proposta abarca a vivência das coordenadoras e professores atuantes nos cursos da área da saúde, em que são ofertadas disciplinas extensionistas, atrelado ao referencial teórico metodológico Espiral Construtivista (LIMA, 2017). Como alternativa ao distanciamento, foi implementado o ensino remoto das aulas pelos ambientes virtuais de aprendizagem.

Como estratégia de obtenção de informações para descrição da experiência, consultaram-se o relatório das disciplinas extensionistas entregues ao final de cada semestre, as experiências compartilhadas na mostra integrada das disciplinas extensionistas dos cursos da saúde da Universidade, além das respostas dos professores extensionistas ao formulário do Google Forms para acompanhamento das disciplinas extensionistas.

\section{RESULTADOS E DISCUSSÃO}

O projeto de extensão integrador da área da saúde da [texto ocultado] ([texto ocultado]), nomeado de Atenção integral à saúde como estratégia para a integração ensino-serviço-comunidade, pertence aos cursos de Biomedicina; Enfermagem; Farmácia; Fisioterapia; Nutrição; Odontologia; Psicologia; Terapia Ocupacional.

Os objetivos do projeto são qualificar o processo de integração ensino-serviço-comunidade, visando promover a educação interprofissional e a atenção integral à saúde. Cada curso criou subprojetos extensionistas que pudessem estar unidos entre disciplinas do mesmo curso ou de outros cursos com objetivos afins. Em 2020, foram submetidos na plataforma da universidade 33 subprojetos extensionistas da área da saúde. Considerando a realidade e as especificidades do trabalho em saúde, que é desenvolvido por seres humanos para outros seres humanos, cuja complexidade ultrapassa os saberes de uma única profissão, é que tem se defendido que o trabalho em saúde deve envolver práticas 
multiprofissionais por uma necessidade própria da evolução do conhecimento e da complexidade que vão assumindo os problemas de saúde na realidade atual (MATOS, 2009).

A partir do momento em que se iniciou o distanciamento social, foram propostas atividades remotas de promoção de saúde, buscando diversificar as metodologias com base em adaptações das atividades já idealizadas. O referencial teórico de trabalho utilizado pelos subprojetos de ensino-extensão participantes a Espiral Construtivista, que consiste em identificar os problemas; formular as explicações; elaborar as questões; buscar novas informações; construir novos significados e avaliar o processo (LIMA, 2017).

Durante o ano de 2020, os cursos adptaram o referencial teórico-metodológico da Espiral Construtivista, mantendo a previsão inicial de utilizá-la como metodologia dos subprojetos. Nas aulas síncronas foi realizada a contextualização da atuação do profissional no campo de prática, mediada pela vivência do professor, para que o aluno pudesse conhecer o diagnóstico situacional e posteriormente a aplicação da metodologia da Espiral Construtivista.

Nesta atividade, buscou-se exercitar o senso crítico e reflexivo do estudante para perceber as possibilidades/necessidades de atenção e cuidado. O processo avaliativo dos estudantes iniciou, portanto, com a elaboração pelos mesmos a partir das aulas teóricas da realização do diagnóstico situacional da população e posterior aplicação das etapas do método, descritas na metodologia.

Além disso, para complementar as avaliações foram desenvolvidas avaliações teóricas, seminários avaliativos e casos clínicos. Esse novo contexto exigiu dos docentes uma metodologia que fortalecesse a articulação do conhecimento teórico-prático e buscasse novos caminhos de ensino que foquem no protagonismo dos estudantes, favoreçam a motivação e estimulem a autonomia destes (CACHAPUZ et al., 2011).

Os subprojetos foram desenvolvidos de diversas formas para atingir seu público, através da divulgação de materiais educativos em redes sociais no formato de folders, visando a facilidade de impressão (quando possível) e, também, a facilidade em compartilhar pelas redes sociais, envio por e-mail, conversas com por videoconferência e até mesmo envio de material impresso que chegou aos locais através dos professores das disciplinas. Para que todos os cursos pudessem socializar seus projetos, as coordenadoras do projeto de extensão realizaram em cada semestre a Mostra Integrada das Disciplinas Extensionistas na plataforma Meet.

Durante o ano foram envolvidos 1083 estudantes dos cursos e estima-se que aproximadamente o número de pessoas da comunidade atendidas e o alcance nas redes sociais foi em torno 32.483 . Os desafios e avanços da experiência da curricularização da extensão universitária na área da saúde durante a pandemia de Covid-19 estão apresentados no quadro 1, respostas coletadas pelo formulário do Google Forms enviado aos professores. 
Quadro 1 - Desafios e avanços da experiência da curricularização da extensão universitária na área da saúde durante a pandemia de Covid-19. Santa Maria, RS, Brasil, 2020.

\begin{tabular}{|c|c|}
\hline Des & Avanços das Disciplinas Extensionistas de forma remota \\
\hline $\begin{array}{l}\text { - Apresentar o diagnóstico situacional, sem os alunos irem } \\
\text { na comunidade; } \\
\text { - Encontrar um modo para facilitar o conhecimento dos } \\
\text { alunos acerca dos diferentes serviços de saúde que cons- } \\
\text { tituem a Rede de Atenção à Saúde, já que não foi possível } \\
\text { realizar visitas presenciais. } \\
\text { - Incentivar os alunos a desenvolverem trabalhos criativos; } \\
\text { Propor extensão de forma remota, em meio a pandemia e } \\
\text { com restrições de imagem e vídeo. } \\
\text { Promover a efetiva integração dos estudantes com a } \\
\text { comunidade; } \\
\text { Pensar em estratégias e tecnologias para abordar a comu- } \\
\text { nidade. } \\
\text { Os impactos que a pandemia nos trouxe no quesito } \\
\text { restrição de visitações a territórios potencialmente frágeis } \\
\text { e com populações de risco, além do fato da quantidade de } \\
\text { visitas à comunidade. } \\
\text { - Estimular os estudantes a compreenderem a necessidade } \\
\text { de não somente planejar as ações, mas implementá-las, } \\
\text { mesmo que de modo remoto; } \\
\text { - Necessidade de investir em uma compreensão ampliada } \\
\text { da extensão juntamente ao grupo de estudantes. } \\
\text { sionistas desenvolvidas. }\end{array}$ & $\begin{array}{l}\text { - Alcance maior nas redes sociais, interação com pessoas } \\
\text { de outras localidades; } \\
\text { - Ampliação da autonomia dos estudantes, capacidade de } \\
\text { expansão dos territórios de abrangência; } \\
\text { - O ambiente remoto contribuiu para que as realizações } \\
\text { de reuniões com a equipe pudessem ser feitas com mais } \\
\text { frequência, assim como a divulgação, em redes sociais, } \\
\text { do material referente a política e as suas ações; } \\
\text { - Maior divulgação dos materiais produzidos de forma digital; } \\
\text { - As ações planejadas no desenvolvimento da disciplina } \\
\text { auxiliarão os colaboradores dos serviços de saúde visando } \\
\text { à incorporação de novas práticas que resultem em mais } \\
\text { segurança no desenvolvimento de suas atividades laborais; } \\
\text { - Mesmo de forma virtual, os alunos puderam visualizar } \\
\text { um cenário de prática real, contribuindo para a sua cons- } \\
\text { trução acadêmica e para a qualificação da assistência nas } \\
\text { instituições parceiras, nos seus colaboradores e para os } \\
\text { usuários do local; } \\
\text { - Fortalecimento dos laços do serviço com a instituição de } \\
\text { ensino durante o período da pandemia; } \\
\text { - Variedade de material elaborado para abordar temáticas } \\
\text { importantes; } \\
\text { - Necessidade de diversificar as estratégias de ensino e } \\
\text { aprendizagem de modo a planejar e implementar ações } \\
\text { extensionistas que alcancem a comunidade; } \\
\text { sões e reflexões sobre as ações estratégicas. }\end{array}$ \\
\hline
\end{tabular}

Fonte: Elaborado pelas autoras.

Os resultados mostram que os avanços percebidos pelos docentes foi poder explorar o meio virtual para maior divulgação e alcance de informações, assim como o meio virtual agilizou e otimizou reuniões e encontros com a comunidade e estudantes. $\mathrm{O}$ meio virtual foi uma estratégia durante a pandemia para disseminar conteúdos de forma acessível e possível, e serviu como um potencializador do fluxo comunicacional (FALCÃO, 2020).

Dentro das habilidades e competências a serem desenvolvidas pelos estudantes, a produção de materiais para o meio digital contribuiu para que ele tivesse mais autonomia no seu processo de aprendizagem e para que ele entendesse o seu papel enquanto educador em saúde, criando materiais informativos em linguagem acessível à população a partir de fontes técnicas e evidências científicas. Nesse processo, o estudante pode cumprir com seu papel acadêmico e social de disseminar os conhecimentos produzidos no campo acadêmico para fora dos muros da universidade, fazendo com que a ação de pesquisar possa transformar realidades (FALCÃO, 2020). 
Entre os desafios encontrados pelo distanciamento social está a dificuldade na realização do diagnóstico social, de conhecer os diferentes serviços de saúde e de abordar de forma presencial a comunidade, porém isso tirou o docente e discente de sua zona de conforto e fez com que inovasse e trouxesse novas formas de comunicação. Os docentes tiveram que apresentar os locais de práticas aos seus estudantes, não mais de forma presencial, mas através de relatos e depoimentos de profissionais de saúde atuantes nas comunidades e de contato virtual com pessoas da comunidade. Isso fez com que se compreendesse que a nova visão de extensão universitária é parte integrante da dinâmica pedagógica curricular e faz parte do processo de formação e produção do conhecimento, em que promove a alteração da estrutura rígida dos cursos para uma flexibilidade curricular que possibilite a formação crítica. Esta formação permitirá aos estudantes analisarem a extensão de forma ampliada e ao mesmo tempo de poder observar as potencialidades desenvolvidas no contexto universitário pandêmico (SÁ, 2021).

\section{CONCLUSÃO}

A experiência da curricularização da extensão universitária na área da saúde durante a pandemia de Covid-19 no ano de 2020 demonstrou que as atividades extensionistas desenvolvidas nos subprojetos promoveram a educação interprofissional e a atenção integral à saúde das comunidades desenvolvidas de forma virtual ou pelo envio de materiais para a comunidade. De tal forma, como os trabalhos foram publicados em redes sociais, ainda teve um alcance maior de pessoas beneficiadas.

Além de um olhar diferenciado para as demandas das comunidades, os estudantes se colocaram no papel de profissionais da saúde e se empenharam em levar os conhecimentos adquiridos nas disciplinas para a sua vivência na prática.

A metodologia desenvolvida no projeto integrador Atenção integral à saúde como estratégia para a integração ensino-serviço-comunidade, contribuiu para o estudante entender o seu papel no desenvolvendo novas habilidades frente às disciplinas extensionistas junto às necessidades da comunidade no contexto pandêmico.

\section{REFERÊNCIAS}

BISCARDE, D. G. S.; PEREIRA-SANTOS, M.; SILVA, L. B. Formação em saúde, extensão universitária e Sistema Único de Saúde (SUS): conexões necessárias entre conhecimento e intervenção centradas na realidade e repercussões no processo formativo. Interface (Botucatu), Botucatu, v. 18, n. 48, p. 177-186, 2014. Disponível em: https://bit.ly/3jmG21V. Acesso em: 13 Set. 2020.

BRASIL. Lei n 13.005 de 25 de junho de 2014. Aprova o Plano Nacional de Educação - PNE e dá outras providências. Disponível em: https://bit.ly/2XsdKLE. Acesso em: 29 set. 2020. 
BRASIL. Projeto de Lei do Plano Nacional de Educação (PNE 2011-2020): projeto em tramitação no Congresso Nacional - PL nº 8.035/2010. Brasília, DF: Edições Câmera, 2011. (Série Ação Parlamentar, 436). Disponível em: https://bit.ly/3DXTPnE. Acesso em: 29 set. 2020.

CACHAPUZ, A.; GIL-PÉREZ, D.; CARVALHO, A. M. P.; PRAIA, J.; VILCHES, A. A necessária renovação do Ensino das Ciências. 3.ed. São Paulo: Cortez, 2011.

Deslandes, M. S. S., Arantes, A.R. The university extension as a mean of social and professional transformation. Sinapse Múltipla, 2017. Disponível em: https://bit.ly/3aRluKq. Acesso em: 29 set. 2020.

FALCÃO, D.; GOMES, C. L. Estratégia e Táticas do Projeto "Cine Luce" no Contexto Pandêmico da Covid-19: O Lazer em Foco. LICERE - Revista do Programa de Pós-graduação Interdisciplinar em Estudos do Lazer, [S. l.], v. 23, n. 3, p. 27-56, 2020. DOI: 10.35699/2447-6218.2020.25079. Disponível em: https://bit.ly/3AYNNRI. Acesso em: 6 jun. 2021.

GADOTTI, M. Extensão Universitária: Para quê? São Paulo: Instituto Paulo Freire, 2017. Disponível em: https://bit.ly/3jmGrRZ. Acesso em: 29 set. 2020.

LIMA, V. V. Espiral construtivista: uma metodologia ativa de ensinoaprendizagem. Interface (Botucatu), v. 21, n. 61, p. 421-34, 2017. Disponível em: https://bit.ly/3pksFTH. Acesso em: 13 set. 2020.

MATOS, E.; PIRES, D. E. P.; SOUSA, G. W. Relações de trabalho em equipes interdisciplinares: contribuições para novas formas de organização do trabalho em saúde. Rev. bras. enferm., Brasília, v. 63, n. 5, p. 775-781, Out. 2010. Disponível em: https://bit.ly/3G6FvLe. Acesso em: 13 set. 2020.

SÁ, I. S. S. O.; SOUZA, L. D., ALVES, R. M. A., AZEVEDO, S. S. Desafios na Execução de Projetos de Extensão Universitária e Responsabilidade Social em Contexto de Pandemia: Percepção de Gestores Docentes. Id onLine Rev. Mult. Psic., v. 15, n. 55, p. 743-754, Maio/2021.

SILVA, A. F. L.; RIBEIRO, C.D.M.; SILVA JÚNIOR, A. G. Pensando extensão universitária como campo de formação em saúde: uma experiência na Universidade Federal Fluminense, Brasil. Interface (Botucatu), Botucatu, v. 17, n. 45, p. 371-384, 2013. Disponível em: https://bit.ly/2ZctdAr. Acesso em: 13 Set. 2020. 